\title{
Endoscopic findings in uninvestigated dyspepsia
}

\author{
Jacob Jehuda Faintuch ${ }^{1,3^{*}}$, Fernando Marcuz Silva ${ }^{1}$, Tomás Navarro-Rodriguez ${ }^{2}$, Ricardo Correa Barbuti \\ Claudio Lyoiti Hashimoto ${ }^{2}$, Alessandra Rita Asayama Lopes Rossini ${ }^{2}$, Marcio Augusto Diniz ${ }^{2}$ and Jaime Natan Eisig ${ }^{2}$
}

\begin{abstract}
Background: It is important to know the causes of dyspepsia to establish the therapeutic approach. Dyspepsia is a frequent syndrome in our country, where there are restrictions to endoscopy and high prevalence of Helicobacter pylori (H. pylori) infection. This study aimed to assess the endoscopic findings of the syndrome, in an outpatient screening clinic of a tertiary hospital in São Paulo.

Methods: Outpatients with uninvestigated dyspepsia, according to Rome III criteria, answered a dyspepsia questionnaire and underwent esophagogastroduodenoscopy. The Rapid Urease Test was applied to fragments of the antral mucosa and epidemiological data were collected from the studied population. Organic dyspepsia findings were analyzed with different variables to verify statistically significant associations.

Results: Three hundred and six patients were included and 282 were analyzed in the study. The mean age was 44 years and women comprised $65 \%$ of the sample. Forty-five percent of the patients reported alarm symptoms. Functional dyspepsia was found in $66 \%$ of the patients (20\% with normal endoscopy results and $46 \%$ with gastritis), $18 \%$ had GERD and 13\% had ulcers (duodenal in 9\% and gastric in 4\%). Four cases of gastric adenocarcinoma were identified (1.4\%), one without alarm characteristics, 1 case of adenocarcinoma of the distal esophagus and 1 case of gastric lymphoma. The prevalence of $\mathrm{H}$. pylori was $54 \%$ and infection, age and smoking status were associated with organic dyspepsia. The age of 48 years was indicative of alarm signs.
\end{abstract}

Conclusions: The endoscopic diagnosis of uninvestigated dyspepsia in our setting showed a predominance of functional disease, whereas cancer was an uncommon finding, despite the high prevalence of H. pylori. Organic dyspepsia was associated with infection, age and smoking status.

Keywords: Dyspepsia findings, Esophagitis, Functional dyspepsia, Gastric cancer, Peptic ulcer

\section{Background}

Dyspepsia is a prevalent complaint in general practice and gastrointestinal clinics [1-5], with a prevalence of up to $40 \%$ among adults in Brazil [6]. Dyspepsia represents up to $8.3 \%$ of all primary care physician visits and causes huge economic costs to patients and to the economy [7]. Rome III guideline states that dyspepsia is non-reflux predominant pain or discomfort in the upper abdomen and the patients must also have one or more of the following four symptoms: postprandial fullness, early satiation, epigastralgia and epigastric burning. Symptom onset must

\footnotetext{
* Correspondence: faintuch@zipmail.com.br

'Division of Clinical Medicine and Propaedeutic Clinic of Hospital das Clínicas da Faculdade de Medicina da USP, São Paulo, Brasil

${ }^{3}$ Hospital das Clínicas da Faculdade de Medicina da Universidade de São Paulo, Av. Dr. Enéas de Carvalho Aguiar, 155 - Cerqueira César, São Paulo, SP, Brasil

Full list of author information is available at the end of the article
}

have occurred at least six months prior to diagnosis [8]. Only $75 \%$ of the dyspepsia experts, $73 \%$ of gastroenterologists and $59 \%$ of primary care providers adhere to dyspepsia best practices; so "dyspepsia" means different things to different providers. Without a common diagnostic language, general practitioners may be unable to provide adequate treatment following common dyspepsia guidelines. [9]. The rapid introduction of new diagnostic criteria for dyspepsia has made very difficult or virtually impossible to compare prevalence rates from different periods or geographic regions [10]. Because structural upper gastrointestinal (UGI) tract diseases, such as peptic ulcer, erosive esophagitis, luminal strictures and malignancy can course with dyspepsia, esophagogastroduodenoscopy (EGD) is the diagnostic procedure of choice to differentiate patients with organic from those with functional dyspepsia [11]. Although it is possible to propose endoscopy as the initial
C Biomed Central

(c) 2014 Faintuch et al.; licensee BioMed Central Ltd. This is an open access article distributed under the terms of the Creative Commons Attribution License (http://creativecommons.org/licenses/by/2.0), which permits unrestricted use, distribution, and reproduction in any medium, provided the original work is properly cited. 
strategy for dyspepsia [12], the establishment of this procedure for every dyspeptic patient may not be practical approach, as the high prevalence of the syndrome will result in very high costs to any health system [13]. Moreover, the diagnostic procedure and its cost effectiveness must be considering that a large number of uninvestigated dyspepsia are functional cases [14]. Thus, the use of endoscopy in the management of uninvestigated dyspepsia remains a controversial issue worldwide [11]. The frequency of uninvestigated dyspepsia varies considerably in different populations and such differences may be related to true differences in the frequency of the condition or the criteria used to diagnose dyspepsia [15]. International medical practice and academic associations have recommended using alarm signs with or without age limits, usually set at 50-55 years, to select dyspeptic patients for endoscopy [16]. The predictive values to be used in the diagnosis of upper gastrointestinal pathology have been extensively studied, but the results are inconsistent, especially because the majority of previous studies were carried out in Europe or North America [16-18]. As for our country, the very high prevalence of $H$. pylori infection [19-22], which requires a complex and expensive treatment for a large number of individuals and the low availability of noninvasive tests for the diagnosis of $H$. pylori infection make the test and treat approach unfeasible. The age indication for endoscopy has not been determined in our country and the limited availability of this procedure does not allow it to be requested as the initial approach.

By prospectively following consecutive patients with uninvestigated dyspepsia in an outpatient screening clinic from a tertiary hospital, this study aimed to assess the diagnostic effectiveness of EGD, in a developing country.

\section{Methods}

\section{Study patients and setting}

This prospective observational study was carried out in a tertiary hospital, which provides open-access service to endoscopy. From September 2008 and September 2011, consecutive adult outpatients who presented with uninvestigated dyspepsia were screened for eligibility. All study participants were systematically evaluated before undergoing endoscopy. The patients were interviewed to determine the presence of alarm symptoms, including unintended weight loss (defined as decrease of more than $5 \%$ of original body weight in three months), symptoms suggestive of upper gastrointestinal bleeding and dysphagia. Older age, presence of mass or lymphadenopathy and family history of upper gastrointestinal cancer were not included as alarm characteristics. Symptom intensity was determinate by the Leeds Dyspepsia Questionnaire [23] and epigastralgia was considered typical when pain was relieved by food or acid suppression or clocking was present. The present study was carried out by only two physicians, who made the interviews in person with the outpatients using a standardized questionnaire. The upper digestive endoscopy was carried out with a standard electronic videoendoscope by two experienced endoscopists, no later than 20 days after the interview, to allow time for the symptomatic use of antacids. H. pylori determination was performed by the Rapid Urease Test, validated in our country [24].

\section{Inclusion criteria}

Epigastralgia or epigastric burning lasting for at least three months, with symptom onset having occurred at least six months before, at least once a week and/or at postprandial fullness or early satiation, for three months, with symptom onset that started at least six months before, at least once a week. Patients should be younger than 90 and older than 13 years old.

\section{Exclusion criteria}

Exclusion criteria included predominant symptoms of gastroesophageal reflux disease (GERD), symptoms outside the epigastrium, other predominant dysmotility symptoms (nausea and vomiting), use of NSAIDs (including low dose treatment) up to one week before study inclusion, use of proton pump inhibitors or H2-blockers for more than two weeks, before study enrollment, presence of systemic decompensated disease (congestive heart failure, coronary heart disease, liver failure, diabetes mellitus, thyroid disease, acute or chronic respiratory failure, hematological diseases), presence of major psychiatric disorders, impediment to endoscopy and difficulty for the patient to understand the aims and procedures of the study.

\section{Ethics}

This study was approved by the Ethics Committee for Analysis of Research Projects - CAPPesq - Clinical Direction of the Hospital and the Faculty of Medicine, University of São Paulo. Written informed consent was obtained from the patients prior to study participation.

\section{Statistical analysis}

Variables were measured as frequency and percentage and the association between organic dyspeptic findings and the variables was determined by Fisher's test, with a $\mathrm{p}$ value $<0.05$ being considered statistically significant. A cutoff for age was obtained though ROC curve.

Organic dyspeptic findings were analyzed with the variables by simple and multiple binary logistic regressions then odd ratios and its 95\% confidence intervals were presented. A score for endoscopy indication was determined based on regression coefficient values. Calculations were performed using $\mathrm{R}$ (The R Foundation for Statistical Computing), version 2.15.2. 
Table 1 Demographic informations of patients studied

\begin{tabular}{ll}
\hline Patients included & 306 \\
Endoscopies performed & $282(92 \%)$ \\
Positive H. pylori & $144(54 \%)$ \\
Age-mean years & 44 \\
$\quad$ Range & $16-87$ \\
$\quad$ Age $>$ 48 & $121(42 \%)$ \\
Male gender & $98(35 \%)$ \\
Race- white & $203(72 \%)$ \\
Born in São Paulo & $120(43 \%)$ \\
Smokers & $45(16 \%)$ \\
\hline
\end{tabular}

\section{Results}

Three hundred six patients were included, of which 282 were available for analysis: 8 patients dropped from the study, 5 were excluded, as they were using of omeprazole at the time of the endoscopy, 4 had their endoscopy results lost, 3 refused to undergo endoscopy, 3 underwent the endoscopy after more than 30 days and one had a previous abdominal surgery.

Patient demographic data are shown in Table 1 and symptoms are listed in Table 2.

GERD (18\%) and peptic ulcer (13\%) were the major causes of organic dyspepsia; there were six cases $(2 \%)$ of upper gastrointestinal cancer (4 gastric carcinomas, 1 gastric lymphoma and 1 esophageal adenocarcinoma) characterizing a total of 96 (34\%) patients as having organic

\section{Table 2 Description of the symptoms}

\begin{tabular}{ll}
\hline Symptoms onset & \\
6 to 11 months & $144(51 \%)$ \\
1 to 3 years & $75(26 \%)$ \\
4 to 10 years & $35(12 \%)$ \\
More than 10 years & $28(10 \%)$ \\
Type of symptoms & \\
$\quad$ Epigastralgia & $193(68 \%)$ \\
Post-prandial fullness & $89(32 \%)$ \\
Intensity of symptoms & \\
Mild & $62(22 \%)$ \\
Moderate & $125(44 \%)$ \\
Severe & $94(33 \%)$ \\
Pain specificity & \\
Tipic & $113 / 192(59 \%)$ \\
Atipic & $79(41 \%)$ \\
Alarm symptoms & \\
Weight loss & $101(36 \%)$ \\
Bleeding & $14(5 \%)$ \\
Dysphagia & $11(4 \%)$ \\
\hline
\end{tabular}

Table 3 General endoscopic findings

\begin{tabular}{cl}
\hline Functional dyspepsia & $186(66 \%)$ \\
Normal examen & $56(20 \%)$ \\
Gastritis & $130(46 \%)$ \\
Organic dyspepsia & $96(34 \%)$ \\
Reflux esophagitis & $52(18 \%)$ \\
Peptic ulcer & $38(13 \%)$ \\
Gastric & $12(4 \%)$ \\
Duodenal & $26(9 \%)$ \\
Malignancy & $6(2 \%)$ \\
Gastric adenocarcinoma & $4(1.4 \%)$ \\
Gastric lymphoma & $1(0.4 \%)$ \\
Esophageal adenocarcinoma & $1(0.4 \%)$ \\
\hline
\end{tabular}

dyspepsia (Table 3). Reflux disease included cases of erosive esophagitis, Barrett's esophagus and esophageal ulcer. The specific findings on upper digestive endoscopy are summarized in Table 4. Organic dyspepsia (determined by

\section{Table 4 Specific endoscopic findings}

\begin{tabular}{ll}
\hline Esophagus & \\
Non-erosive esophagitis* & $8(3 \%)$ \\
Erosive esophagitis & $47(16 \%)$ \\
Barret & $2(0.7 \%)$ \\
Ulcer & $1(0.4 \%)$ \\
Others** $^{*}$ & $10(4 \%)$
\end{tabular}

Stomach

Gastritis

$186(61 \%)$

Enanthematous
Erosive
Nodular
Atrophic

$66(23 \%)$

$95(34 \%)$

$18(6 \%)$

$7(3 \%)$

Ulcer 14 (5\%)

Fundus, body and antrum $\quad 9(3 \%)$

Prepyloric $5(2 \%)$

Malignancy $\quad 5(1.8 \%)$

Adenocarcinoma $\quad 4(1.4 \%)$

Lymphoma $1(0.4 \%)$

Others $6(2 \%)$

Duodenum

$\begin{array}{ll}\text { Duodenitis } & 31(11 \%) \\ \quad \text { Enanthematous } & 9(3 \%) \\ \quad \text { Erosive } & 22(8 \%) \\ \text { Ulcer } & 6(9 \%) \\ \text { Others } & 10(4 \%)\end{array}$

*Non erosive esophagitis: enanthematous esophagitis: 6 cases, esophageal candidiasis: 2 cases.

**Others esophagus findings: Hiatal hernia: 6 cases, Papillomatosis esophagitis: 2 cases, Esophageal variz: 1 case, Retention cyst: 1 case. 
Table 5 Organic dyspepsia in simple binary logistic regression with variables

\begin{tabular}{lllll}
\hline Variable & Group & OR & $\mathbf{9 5 \% ~ C I}$ & $\boldsymbol{p ~ V a l u e}$ \\
\hline Gender & Male & 1.54 & $0.92-2.56$ & 0.10 \\
Age & $>48$ & 1.75 & $1.06-2.87$ & 0.03 \\
Smoking & Positive & 1.4 & $1.21-4.4$ & 0.01 \\
Weight loss & Positive & 0.7 & $0.42-1.18$ & 0.18 \\
Symptom Intensity & Severe & 0.56 & $0.28-1.11$ & 0.10 \\
Symptom duration & $>10$ years & 0.67 & $0.28-1,62$ & 0.37 \\
H. pylori & Positive & 1.67 & $1.06-2.87$ & 0.05 \\
\hline
\end{tabular}

the finding of reflux disease or peptic ulcer or malignancy) showed statistical significance with age, $H$. pylori positive status and smoking, but not with weight loss, symptom intensity and duration, gender and ethnicity (Table 5).

The age of patients analyzed by ROC curve showed that the age of 48 years had a 0.42 positive and 0.72 negative predictive values for organic dyspepsia (Figure 1), suggesting this age is an alarm characteristic.

The coefficients of multiple binary logistic regression of age, treated as a continuous variable, smoking status and positive $H$. pylori status (Table 6) allowed the construction of a score, where values lower than 46 (in a scale of up to 100 points) indicates the non- necessity of EGD with a high negative predictive value for organic dyspepsia (Figure 2).

\section{Discussion}

Our study shows results that are consistent with the meta-analysis by Ford [14], although (considering the Rome criteria) our prevalence of GERD was somewhat higher than that of peptic ulcer, whereas malignancy rates were somewhat higher than those observed in that study. These differences may be due to the fact that our institution is an outpatient screening clinic in general practice of a tertiary hospital. In patients followed in a three-year prospective general practice study, the presence of alarm symptoms significantly increased the risk of developing peptic ulcers, but not gastrointestinal cancer. Positive predictive values for development of cancer and ulcer were $4 \%$ and $14 \%$, respectively [18]. Patients with peptic ulcer were more likely to present with gastrointestinal bleeding [25] and in our study, gastrointestinal bleeding was an uncommon alarm symptom (5\%), whereas the prevalence of peptic ulcer was $13 \%$ and malignancy, $2 \%$. It was somewhat surprising that more than two fifths of our functional dyspeptic patients had alarm symptoms, while about $75 \%$ of the ulcer patients did not. It is possible that our most frequent alarm symptom (weight loss) was not specific for serious digestive tract diseases.

Upper GI bleeding and unintended weight loss were also associated with malignancy [26], but the sensitivity of alarm features in diagnosing upper gastrointestinal malignancy varied from $0 \%$ to $100 \%$, while specificity ranged from $16 \%$ to $98 \%$ [27]. This wide variation in sensitivity may be due to the small number of cancer cases detected in many of the studies. Five in six patients with neoplasms had alarm symptoms, inferring a sensitivity of $83 \%$ and specificity of $59 \%$. In a study with unsedated transnasal esophagogastroduodenoscopy, cancer was found in $4 \%$ of patients with alarm symptoms (in our study $1.7 \%$ ) versus $0.1 \%$ (in our study $0.6 \%$ ) in the non-alarm symptom group [27]. Despite the difference between patients with and without alarm symptoms, it is known that symptoms have limited value in the diagnosis of upper gastrointestinal malignancy [28].

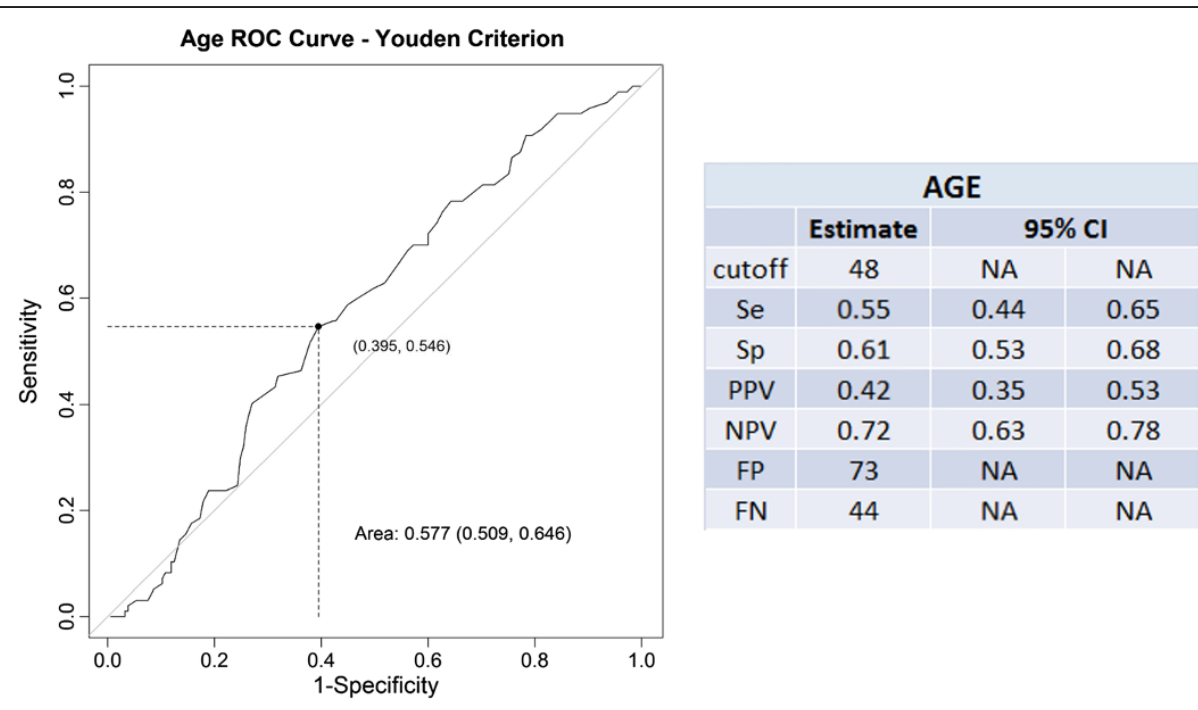

Figure 1 Age indication for alarm feature. 
Table 6 Organic dyspepsia in multiple binary logistic regression

\begin{tabular}{lllll}
\hline Variable & Group & OR & 95\% Cl & pValue \\
\hline Age & $>48$ & 1.92 & $1.13-3.25$ & 0.02 \\
Smocking & Positive & 2.36 & $1.19-4.69$ & 0.01 \\
H. pylori & Positive & 1.68 & $0.99-2.86$ & 0.05 \\
\hline
\end{tabular}

In this study, older age, mass or lymphadenopathy and family history of upper gastrointestinal cancer were not included as alarm features. In Brazil there is no consensus on this matter and the AGA guidelines are usually followed [16]. In our sample, all patients with malignancy were older than 55 years, but considering the finding of organic dyspepsia (reflux disease, peptic ulcer and malignancy) our study suggests the age of 48 as indicative of alarm symptom.

Frequent vomiting was not considered an alarm symptom, as it was disregarded when reported as a chief complaint in dyspeptic syndrome and thus, it is unlikely that this symptom, when present for at least three months, will not result in weight loss.

The presence of adenopathy or abdominal tumor changes the diagnosis of undiagnosed dyspepsia into undiagnosed adenopathy or tumor and in these cases, the best approach requires imaging assessment and not an esophagogastroduodenoscopy.

Family history of upper gastrointestinal cancer is a type of information that is difficult to obtain, when patients know the cause of the disease, they cannot provide information on its type and precise location.

Primary gastrointestinal lymphoma is a rare disease, although the stomach is the most frequent site of involvement for this neoplasm [29]. Our sample had only
1 case of lymphoma; considering the small sample size of our study, this finding was most likely fortuitous.

The prevalence of GERD has increased dramatically in recent decades, mostly in the western world, where it affects about $19 \%$ to $30 \%$ of the population, increasing the risk for esophageal adenocarcinoma [30]. In this study, GERD was diagnosed in $18 \%$ of patients, similar to the findings of a recent meta-analysis, based on Rome criteria [14]. In Denmark, gastric inflammation was recently found in $11 \%$ of the patients with upper gastrointestinal symptoms [27]; our study did not include histological examination of the gastric mucosa, and thus, gastritis was an endoscopic diagnosis, which after the exclusion of other concurrent diagnoses showing a prevalence of $46 \%$. The prevalence of $H$. pylori infection in our population was high (54\%) and infected individuals had a 10-fold higher probability of having any gastric mucosa lesions than noninfected individuals [31]. Our finding of 38 patients (13\%) with ulcer, 26 of them (9\%) with duodenal ulcer, is also consistent with the high prevalence of infection.

In 2005, in a study of our hospital, the overall H. pylori prevalence was 53\%, assessed in 1478 consecutive endoscopies [32]. We had a similarly high prevalence, indicating that there was no decrease in infection rates during this period.

This high prevalence of infection associated with the low availability of non-invasive tests for its detection prevent the use of the proposed approach of test and treat strategy for undiagnosed dyspepsia. H. pylori eradication treatment is always high cost and complex, with limited efficiency of $88 \%$ [33]. The number of cases of functional dyspepsia responsive to treatment is low [34], as only $50 \%$ of ulcer patients attain symptom resolution [35,36], whereas the symptoms of patients with reflux

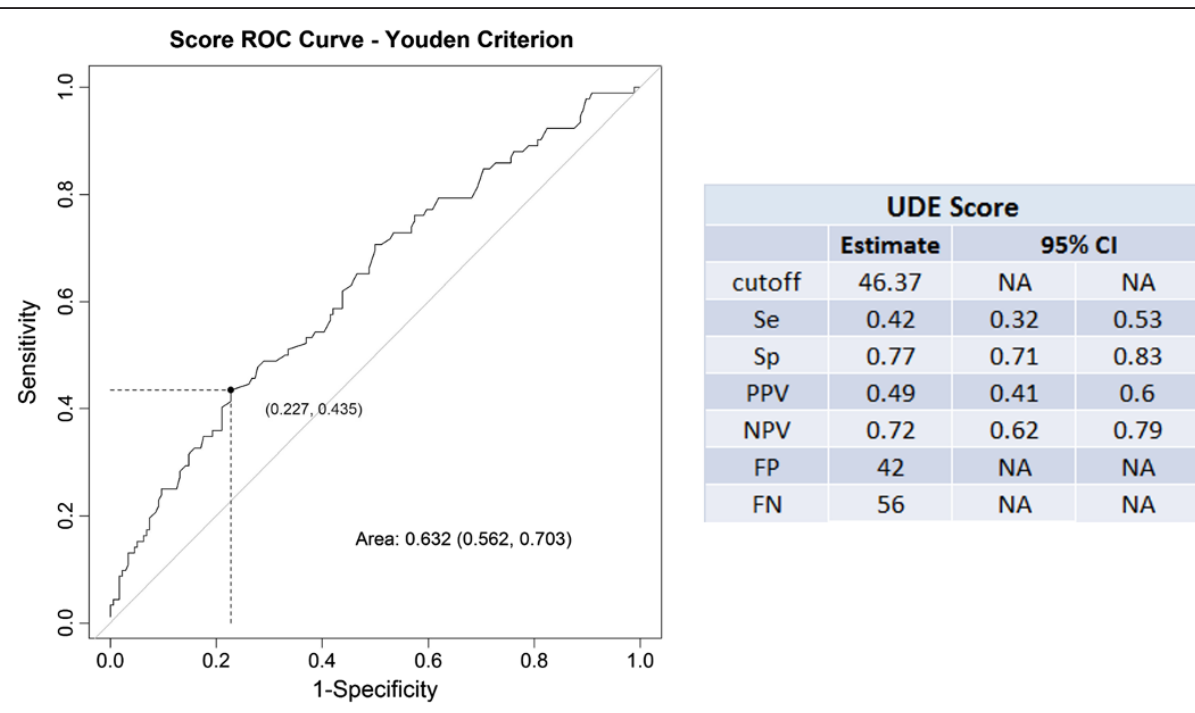

Figure 2 Upper Digestive Endoscopy (UDE) Score. 
disease do not improve with treatment [37]. Therefore, the test and treat strategy may not be adequate for developing countries, which usually have very high prevalence of $H$. pylori infection and low level of resources for health care. Empirical treatment for young patients without alarm signs may be the possible approach for undiagnosed dyspepsia in our country.

Our study provides a score, which can be useful in indicating endoscopy for these cases. Further studies should be performed to test this proposal, especially in centers similar to ours.

\section{Conclusions}

In Brazil, a developing country with high prevalence of H. pylori infection, the most frequent cause of uninvestigated dyspepsia is functional dyspepsia, whereas gastric cancer is a rare finding. Even after selecting patients according to Rome III criteria, reflux disease predominated over peptic ulcer.

The suggested age for the onset of alarm signs is 48 years old and a score that correlates $H$ pylori infection, age and smoking may be useful for the indication of endoscopy as the approach in the presence of dyspepsia.

\section{Competing interests}

The authors declare that they have no competing interests.

\section{Authors' contributions}

All authors contributed to the design of the study. Acquisition of data and quality control: JJF, FMS. Analysis and interpretation of data: JJF, FMS, TNR, RCB,MAD, JNE. Endoscopic examinations: CLH, ARALR. Statistical Analysis: MAD. Draft manuscript: JJF. All authors have read and approved the final manuscript.

\section{Acknowledgement}

Rejane Mattar - PhD - Director of Laboratory of Gastroenterological Functional Tests, by Rapid Urease Test determinations.

\section{Author details}

${ }^{1}$ Division of Clinical Medicine and Propaedeutic Clinic of Hospital das Clínicas da Faculdade de Medicina da USP, São Paulo, Brasil. ${ }^{2}$ Division of Gastroenterology and Clinical Hepatology of Hospital das Clínicas da Faculdade de Medicina da USP, São Paulo, Brasil. ${ }^{3}$ Hospital das Clínicas da Faculdade de Medicina da Universidade de São Paulo, Av. Dr. Enéas de Carvalho Aguiar, 155 - Cerqueira César, São Paulo, SP, Brasil.

Received: 6 February 2013 Accepted: 29 January 2014

Published: 6 February 2014

\section{References}

1. Jones RH, Lydeard SE, Hobbs FD, Kenkre JE, Williams El, Jones SJ, Repper JA, Caldow JL, Dunwoodie WM, Bottomley JM: Dyspepsia in England and Scotland. Gut 1990, 31:401-405.

2. Talley NJ, Zinsmeister AR, Schleck CD, Melton LJ 3rd: Dyspepsia and dyspepsia subgroups: a population-based study. Gastroenterology 1992, 102:1259-1268.

3. Penston JG, Pounder RE: A survey of dyspepsia in Great Britain. Aliment Pharmacol Ther 1996, 10:83-89.

4. Hungin AP, Rubin GP: Management of dyspepsia across the primarysecondary healthcare interface. Dig Dis 2001, 19:219-224.

5. Sobieraj DM, Coleman SM, Coleman Cl: US prevalence of upper gastrointestinal symptoms: a systematic literature review. Am J Manag Care 2011, 17:449-458
6. de Oliveira SS, Santos IS, Silva JFP, Machado EC: Prevalence of dyspepsia and associated sociodemographic factors. Rev Saude Publica 2006, 40:420-427.

7. Sander GB, Mazzoleni LE, Francesconi CF, Balbinotto G, Mazzoleni F, Wortmann AC, Cardoso Ide Q, Klamt AL, Milbradt TC: Influence of organic and functional Dyspepsia on work productivity: the HEROES-DIP study. Value Health 2011, 14(Suppl 1):S126-S129.

8. Tack J, Talley NJ, Camilleri M, Holtmann G, Hu P, Malagelada JR, Stanghellini V: Functional gastroduodenal disorders. Gastroenterology 2006, 130:1466-1479.

9. Spiegel BMR, Farid M, van Oijen MGH, Laine L, Howden CW, Esrailian E: Adherence to best practice guidelines in dyspepsia: a survey comparing dyspepsia experts, community gastroenterologists and primary- care providers. Aliment Pharmacol Ther 2009, 29:871-881.

10. Olafsdottir LB, Gudjonsson H, Jonsdottir HH, Bjornsson E, Thjodleifsson B: Natural history of functional gastrointestinal disorders comparison of two longitudinal population-based studies. Dig Liver Dis 2012, 44:211-217.

11. Hsu YC, Yang TH, Liou JM, Hsu WL, Lin HJ, Wu HT, Lin JT, Wang HP, Wu MS: Can clinical features stratify use of endoscopy for dyspeptic patients with high background prevalence of upper gastrointestinal cancer? Dig Liver Dis 2012, 44:218-223.

12. Bytzer $P$, Hansen JM, Schaffalitzky de Muckadell OB: Empirical H2-blocker therapy or prompt endoscopy in management of dyspepsia. Lancet 1994, 343:811-816.

13. Barkun A, Crott R, Fallone C, Kennedy W, Lachaine J, Levinton C, Armstrong D, Chiba N, Thomson A, Veldhuyzen van Zanten S, Sinclair P, Escobedo S, Chakraborty B, Smyth S, White R, Kalra H, Nevin K: A one-year economic evaluation of six alternative strategies in the management of uninvestigated upper gastrointestinal symptoms in Canadian primary care. Can J Gastroenterol 2010, 24:489-498.

14. Ford AC, Marwaha A, Lim A, Moayyedi P: What is the prevalence of clinically significant endoscopic findings in subjects with dyspepsia? Systematic review and meta-analysis. Clin Gastroenterol Hepatol 2010, 8:830-837.

15. Ghoshal UC, Singh R, Chang FY, Hou X, Wong BC, Kachintorn U: Epidemiology of uninvestigated and functional dyspepsia in Asia: facts and fiction. J Neurogastroenterol Motil 2011, 17:235-244.

16. Talley NJ, Vakil NB, Moayyedi P: American gastroenterological association technical review on the evaluation of dyspepsia. Gastroenterology 2005, 129:1756-1780.

17. Malfertheiner P, Megraud F, O'Morain CA, Atherton J, Axon AT, Bazzoli F, Gensini GF, Gisbert JP, Graham DY, Rokkas T, El-Omar EM, Kuipers EJ, European Helicobacter Study Group: Management of Helicobacter pylori infection-the Maastricht IV/ Florence Consensus report. Gut 2012, 61:646-664.

18. Meineche-Schmidt $\mathrm{V}$, Jorgensen $\mathrm{T}$ : "Alarm symptoms" in patients with dyspepsia: a three year prospective study from general practice. Scand J Gastroenterol 2002, 37:999-1007.

19. Rodrigues MN, Queiroz DM, Rodrigues RT, Rocha AM, Braga Neto MB, Braga LL: Helicobacter pylori infection in adults from a poor urban community in northeastern Brazil: demographic, lifestyle and environmental factors. Braz J Infect Dis 2005, 9:405-410.

20. Santos IS, Boccio J, Santos AS, Valle NC, Halal CS, Bachilli MC, Lopes RD: Prevalence of Helicobacter pylori infection and associated factors among adults in Southern Brazil: a population-based cross-sectional study. BMC Public Health 2005, 5:118.

21. Souto FJ, Fontes CJ, Rocha GA, de Oliveira AM, Mendes EN, Queiroz DM: Prevalence of Helicobacter pylori infection in a rural area of the state of Mato Grosso, Brazil. Mem Inst Oswaldo Cruz 1998, 93:171-174.

22. Zaterka S, Eisig JN, Chinzon D, Rothstein W: Factors related to Helicobacter pylori prevalence in an adult population in Brazil. Helicobacter 2007, 12:82-88.

23. Moayyedi P, Duffett S, Braunholtz D, Mason S, Richards ID, Dowell AC, Axon AT: The Leeds Dyspepsia Questionnaire: a valid tool for measuring the presence and severity of dyspepsia. Aliment Pharmacol Ther 1998, 12:1257-1262.

24. Domínguez-Bello MG, Michelangeli F, Romero R, Beker B, Lara D, Morera C, Vezga MA, Spardella V, Guelrud M, Pérez ME, Pericchi LR: Modification of Christensen urease test as an inexpensive tool for detection of Helicobacter pylori. Diagn Microbiol Infect Dis 1997, 28:149-152.

25. Milosavljevic T, Kostić-Milosavljević M, Jovanović I, Krstić M: Complications of peptic ulcer disease. Dig Dis 2011, 29:491-493. 
26. Khademi H, Radmard AR, Malekzadeh F, Kamangar F, Nasseri-Moghaddam S, Johansson M, Byrnes G, Brennan P, Malekzadeh R: Diagnostic accuracy of age and alarm symptoms for upper GI malignancy in patients with dyspepsia in a Gl clinic: a 7-year cross-sectional study. PLoS One 2012, 7:e39173.

27. Rolff $H C$, Simonsen $L R$, Rosenberg J: Clinical findings confirm national guidelines regarding primary gastroscopy for upper gastrointestinal symptoms. Dan Med Bull 2011, 58:A4363.

28. Vakil N, Moayyedi P, Fennerty MB, Talley NJ: Limited value of alarm features in the diagnosis of upper gastrointestinal malignancy: systematic review and metaanalysis. Gastroenterology 2006, 131:390-401.

29. Koch P, Berdel WE, Willich NA, Reers B, Hiddemann W, Grothaus-Pinke B, Reinartz G, Brockmann J, Temmesfeld A, Schmitz R, Rübe C, Probst A, Jaenke G, Bodenstein $H$, Junker A, Pott C, Schultze J, Heinecke A, Parwaresch R, Tiemann M, German Multicenter Study Group: Primary gastrointestinal non-Hodgkin's Lymphoma: I. anatomic and histologic distribution, clinical features, and survival data of 371 patients registered in the German multicenter study GIT NHL 01/92. J Clin Oncol 2001, 19:3861-3873

30. Erichsen R, Robertson D, Farkas DK, Pedersen L, Pohl H, Baron JA, Sørensen HT: Erosive reflux disease increases risk for esophageal adenocarcinoma, compared with nonerosive reflux. Clin Gastroenterol Hepatol 2012, 10:475-480.

31. Muller LB, Fagundes RB, Morais CC, Rampazzo A: Prevalence of Helicobacter pylori infection and gastric cancer precursor lesions in patients with dyspepsia. Arq Gastroenterol 2007, 44:93-98.

32. Marques SB, Mattar R, Artifon E: High prevalence of duodenal ulcer in a tertiary care hospital in the city of São Paulo, SP, Brazil. Arq Gastroenterol 2011, 48:171-174.

33. Felga G, Silva FM, Barbuti RC, Navarro-Rodriguez T, Zaterka S, Eisig JN: Clarithromycin-based triple therapy for Helicobacter pylori treatment in peptic ulcer patients. J Infect Dev Ctries 2010, 4:712-716.

34. Mazzoleni LE, Sander GB, Francesconi CF, Mazzoleni F, Uchoa DM, de Bona LR, Milbradt TC, von Reisswitz PS, Berwanger O, Bressel M, Edelweiss MI, Marini SS, Molina CG, Folador L, Lunkes RP, Heck R, Birkhan OA, Spindler BM, Katz N, Colombo Bda S, Guerrieri PP, Renck LB, Grando E, Hocevar de Moura B, Dahmer FD, Rauber J, Prolla JC: Helicobacter pylori eradication in functional dyspepsia: HEROES trial. Arch Intern Med 2011, 171:1929-1936.

35. Maconi G, Sainaghi M, Molteni M, Bosani M, Gallus S, Ricci G, Alvisi V, Porro GB: Predictors of long-term outcome of functional dyspepsia and duodenal ulcer after successful Helicobacter pylori eradication - a 7-year follow-up study. Eur J Gastroenterol Hepatol 2009, 21:387-393.

36. Silva FM, Navarro-Rodriguez T, Barbuti RC, Mattar R, Hashimoto CL, Eisig JN: Helicobacter pylori reinfection in Brazilian patients with peptic ulcer disease: a 5-year follow-up. Helicobacter 2010, 15:46-52.

37. Xinias I, Maris T, Mavroudi A, Panteliadis C, Vandenplas Y: Helicobacter pylori infection has no impact on manometric and $\mathrm{pH}$-metric findings in adolescents and young adults with gastroesophageal reflux and antral gastritis: eradication results to no significant clinical improvement. Pediatr Rep 2013, 5:e3.

doi:10.1186/1471-230X-14-19

Cite this article as: Faintuch et al:: Endoscopic findings in uninvestigated dyspepsia. BMC Gastroenterology 2014 14:19

\section{Submit your next manuscript to BioMed Central and take full advantage of:}

- Convenient online submission

- Thorough peer review

- No space constraints or color figure charges

- Immediate publication on acceptance

- Inclusion in PubMed, CAS, Scopus and Google Scholar

- Research which is freely available for redistribution

Submit your manuscript at www.biomedcentral.com/submit 